ANUARIO DE Estudios MEDIEVALES

46/1, enero-junio de 2016, pp. 203-230

ISSN 0066-5061

doi:10.3989/aem.2016.46.1.06

\title{
FELIPA DE LANCÁSTER, LA DAMA INGLESA QUE FUE MODELO DE REGINALIDAD EN PORTUGAL (1387-1415) ${ }^{1}$
}

\author{
PHILIPPA OF LANCASTER, THE ENGLISH LADY, \\ WHO WAS A QUEENSHIP ROLE MODEL IN PORTUGAL (1387-1415)
}

\author{
MANUELA SANTOS SilVA \\ Universidade de Lisboa
}

\begin{abstract}
Resumen: Hasta hace algunas décadas, el interés mostrado por los historiadores en evaluar el poder ejercido por las reinas portuguesas como consortes o progenitoras de los reyes era casi inexistente. Se conservan, sin embargo, suficientes datos como para poder afirmar que, en la Edad Media portuguesa, algunas reinas ejercieron funciones de naturaleza política y diplomática, y participaron junto a sus maridos en la administración de los bienes de la corona, además de cumplir con los deberes que se les atribuían como esposas y madres. Uno de los casos mejor documentados es el de Felipa de Lancáster, esposa de Juan I de Portugal, a quien llamaremos João I para evitar confusiones causadas por homonimias.
\end{abstract}

Palabras clave: reginalidad; colaboración política; influencia informal; educación; piedad; reformadora.

\begin{abstract}
Until a few decades ago, the historians' interest in the evaluation of the power exercised by the queens, as wives or mothers of the kings who were in charge of the governance of the kingdom, was almost non-existent. However, there are enough data to prove that in Portugal, in the Middle Ages, some queens exerted political and diplomatic functions, participated with their husbands in the administration of the assets of the crown, in addition to fulfilling the obvious obligations of being good wives and mothers. Philippa of Lancaster's -wife of John I of Portugal- queenship is well documented.
\end{abstract}

Keywords: queenship; political partnership; informal influence; education; piety; reformer.

\section{SUMARIO}

1. Los poderes de las reinas de Portugal en la Edad Media.- 2. ¿Quién era Felipa de Lancáster, la única inglesa que fue reina de Portugal?- 3. Las regencias en nombre del marido.- 4. La monarquía compartida.- 5. El papel diplomático en la sombra.5.1. Portugal y Castilla.- 5.2. Portugal y Aragón.- 5.3. Portugal y Granada.- 5.4. Portugal e Inglaterra.- 6. La influencia en la corte.- 7. Bibliografía citada.

${ }^{1}$ Abreviaturas utilizadas: AHCMO = Arquivo Histórico da Câmara Municipal de Óbidos; AN-TT = Arquivo Nacional Torre do Tombo; Ch.P.D. João I = Chancelarias Portuguesas D. João I 2004; Ch.P.D. Duarte = Chancelarias Portuguesas. Dom Duarte 1998.

La versión española de este texto, originalmente escrito en portugués, se debe a mi colega y amiga Covadonga Valdaliso, a quien estoy muy agradecida. Conservaremos los nombres en las formas usadas en sus propios reinos. 


\section{LOS PODERES DE LAS REINAS DE PORTUGAL EN LA EDAD MEDIA}

Aunque a fines del siglo XIX hubo en Portugal diversos autores que mostraron interés por comprender cuáles fueron los papeles que desempeñaron, y los poderes que tuvieron, las reinas en el pasado ${ }^{2}$, a lo largo de la mayor parte del siglo XX los historiadores no consideraron estos temas dignos de ser analizados en mayor profundidad; y ni tan siquiera citados. Curiosamente, quienes más contribuyeron al avance en el conocimiento de las materias relacionadas con el estatuto y el poder de las reinas portuguesas fueron historiadores del Derecho, y en especial Paulo Merêa a través de sus trabajos sobre las concesiones de dotes y arras en los enlaces matrimoniales ${ }^{3}$. Por su parte, el desarrollo dentro de la historiografía en lengua inglesa, en las últimas décadas del siglo XX, de los estudios sobre la llamada queenship -término que aquí traduciremos como "reginalidad", basándonos en los trabajos de Núria Sille$\mathrm{ras}^{4}$ - no tuvo un reflejo inmediato en Portugal. Ello tal vez se debió al peso que en el medievalismo portugués tenía aún por entonces la historiografía francesa; a pesar de que desde fines del siglo XIX venían destacándose las diferencias, tanto con relación a las tradiciones jurídicas como a las prácticas de gobernación monárquicas, que había habido entre ambos reinos.

Paralelamente, los citados estudios sobre la reginalidad por lo general no contaban con datos referentes a Portugal, ni a la Península Ibérica en su conjunto ${ }^{5}$; y sorprendió en su día comprobar, a partir de la publicación de algunas obras colectivas, que esta exclusión de los reinos ibéricos encubría una inesperada originalidad. Tanto en la Península como en otras regiones normalmente no contempladas en las primeras publicaciones, los sistemas monárquicos presentaban importantes diferencias con relación al poder y a las capacidades de actuación de las esposas de los reyes ${ }^{6}$. Se había partido, a mi modo de ver, de una premisa errónea: suponer que el paradigma francés de alejamiento de las mujeres tanto de la sucesión como de las funciones políticas, en vez de ser la excepción, era la regla; y creer que el sistema inglés era el único distinto ${ }^{7}$.

En lo relativo a la investigación portuguesa, fue el desarrollo de los estudios monográficos sobre núcleos urbanos y áreas regionales el que comenzó a revelar, a aquellos que los llevaron a cabo, la existencia de una

${ }^{2}$ Figanière 1859; Benevides 2007; Monteiro 1893.

${ }^{3}$ Merêa 1937, pp. 139-149; 1952, p. 63.

${ }^{4}$ Silleras-Fernández 2003, pp. 119-133.

${ }^{5}$ Stafford 1983, 1998; Parsons 1998; Duggan 1997.

${ }^{6}$ Vann 1993, p. 13; Earenfight 2005, pp. XIII-XIX.

${ }^{7}$ Cosandey 2000, p. 9. 
diversidad de realidades en el funcionamiento de la monarquía. Más concretamente, reveló la autonomía de los miembros de la familia real. En este sentido, y dentro del área de estudios del régimen señorial, fueron pioneros los trabajos de Maria Paula Marçal Lourenço sobre la casa del Infantado ${ }^{8}$ y sobre la casa, corte y patrimonio de las reinas de Portugal (1640-1754) ${ }^{9}$. En lo referente a la Edad Media, también fue el análisis de las bases fiscales y territoriales que financiaban las casas de las reinas el que marcó el arranque de los estudios sobre las capacidades y poderes de dichas reinas en Portugal ${ }^{10}$.

En la terminología medieval la reina era la esposa del rey; un estatuto que aparecía reglamentado en compilaciones legislativas como el Espéculo o las Siete Partidas, ambas de Alfonso X el Sabio, y que se mantenía tras la muerte del monarca. En la documentación más antigua de los reinos de León, Castilla y Portugal el término designaba también a las hijas del rey. Teresa Alfónsez, por ejemplo, hija de Alfonso VI de León y condesa de Portucale, cuando enviudó volvió a titularse regina, siendo como tal reconocida incluso por instancias no ibéricas ${ }^{11}$. Estas denominaciones aunaban principios basados en el Derecho romano con otros quizá nacidos de la praxis que llegó con las tribus designadas como bárbaras $^{12}$-las que se superpusieron a la organización territorial romana- $\mathrm{o}$, tal vez, emanados de tradiciones locales más antiguas. En comunidades de base familiar, con un pasado común de vivencias nómadas y/o guerreras, el papel de las mujeres, y concretamente de la reina, estaba bien definido, y se le atribuían funciones, deberes y derechos que se distinguían claramente de los que definían a quien gobernaba -el rey-; aunque este último papel también pudiese, en coyunturas excepcionales y en casos casi siempre efímeros, ser desempeñado por mujeres.

Asumir la regencia en sustitución del marido ausente, o precozmente fallecido antes de que el hijo heredero hubiese alcanzado una edad aceptable para desempeñar el cargo, era tal vez la más institucional de las funciones que una reina consorte podía ejercer; pero había otras, de mayor importancia para el gobierno del reino, y para la relación de dicho reino con otros territorios, que se confiaban a las reinas -las diplomáticas, por ejemplo-. Siendo casi siempre oriundas de reinos diferentes, muchas veces las reinas podían entrevistarse con interlocutores de peso a través de canales privilegiados. Dado que este tipo de negociaciones, que llevaban a cabo en nombre de sus maridos,

${ }^{8}$ Lourenço 1995.

${ }^{9}$ Lourenço 1999.

${ }^{10}$ Silva 1994, pp. 85-109; Rodrigues 1995, pp. 49-72; Rodrigues, Silva 2010, pp. 209-228.

${ }^{11}$ Amaral, Barroca 2012, p. 377.

${ }^{12}$ Vann 1993, pp. 125-147; Stafford 1983, 1998, p. IX. 
eran casi siempre con familiares, tenían poca visibilidad. Aunque lo mismo puede decirse de sus otras actividades. Como ya explicó Pauline Stafford, la autoridad de las reinas procedía de identidades femeninas a las que se atribuían poderes mayores o menores -hija, esposa, madre, señora de la casa, reina viuda- y, muchas veces, el desempeño de su papel como reinas podía verse ensombrecido por alguna de esas identidades de género que las definían ${ }^{13}$. Su poder era ejercido casi siempre a través de una influencia informal; que, sin embargo, y como señalara Theresa Earenfight, llegaba a ser tan importante como la autoridad oficial ${ }^{14}$.

Más allá de estas facetas, normalmente comunes a todas las reinas, las consortes de los reyes ibéricos, gracias al triunfo y la permanencia de una cierta cultura política que se perdió en otras regiones, lograron gozar durante toda la Edad Media de una autonomía derivada de su estatuto ${ }^{15}$, y de ciertas facilidades que se ponían a su disposición. Nada despreciable era, en este sentido, el hecho de poder disponer, desde el momento de su matrimonio, de las rentas que se obtenían de los derechos reales sobre algunas ciudades y villas del reino, para poder administrar con ellas sus casas autónomamente dentro de la corte regia ${ }^{16}$. Además, en algunos casos, los monarcas parecían considerarlas sus pares políticos, como ya notaron Theresa Earenfight e Isabel de Pina Baleiras ${ }^{17}$.

Con todo, y como ya se indicó, aun habiendo tenido más posibilidades de intervención en materias políticas que sus homólogas en otros territorios occidentales, a lo largo de la Historia las reinas de Portugal no despertaron gran interés; a no ser por factores como su fama de santidad o -en el otro extremo- el haber sido consideradas adúlteras, locas o traidoras. Constituye por ello una excepción el relativo conocimiento que se tiene sobre la única reina inglesa de Portugal, hija primogénita de John of Gaunt -designación coetánea de Gante, la ciudad flamenca en donde había nacido en 1340-, duque de Lancáster y, desde 1371, casado con Constanza, hija de Pedro I de Castilla. Y, aún así, puede decirse que lo que se sabe de Felipa de Lancáster -Philippa of Lancaster originalmente, y conocida en Portugal como Filipa de Lencastre- procede sobre todo de testimonios ajenos, ya que su marido, sus hijos y su casa hablan de sus cualidades, [pero] es sólo a través de su familia como conocemos su perfil ${ }^{18}$.

${ }^{13}$ Stafford 1983, 1998, p. XVIII; Woodacre 2013, p. 1.

${ }^{14}$ Earenfight 2013, pp. 11-12.

${ }^{15}$ Earenfight 2005, p. XIV.

${ }^{16}$ Silva 2013, pp. 271-288.

${ }^{17}$ Earenfight 2005, p. XIV; Baleiras 2012, p. 191.

${ }^{18}$ Entwistle, Russell 1940, pp. 319. 
Ha de admitirse, sin embargo, que -incluso en colecciones de ensayos sobre la llamada medieval queenship-es difícil no comenzar por describir el contexto familiar dentro del cual las reinas actuaban ${ }^{19}$; $y$, aunque el objetivo principal del estudio sea exponer su acción política, ésta camina siempre pareja a sus acciones como madres o esposas ${ }^{20}$. De hecho, cuando su actuación en el dominio público no es obvia, es el papel de las reinas en el mantenimiento de la memoria de sus familias - unido a sus empeños en la promoción de obras piadosas y sociales, y a veces artísticas- el que les concede relevancia ${ }^{21}$.

En el caso concreto de Felipa de Lancáster, y en relación a lo que en la Edad Media se escribió sobre ella, puede decirse que no fue una reina maltratada por los cronistas de su época; pero tampoco le fue dado en las narrativas sobre el reinado de su esposo un especial protagonismo. Fernão Lopes relata sobre todo el periodo anterior a su enlace con João I de Portugal y las condiciones en que éste llegó al trono ${ }^{22}$. Gomes Eanes de Zurara habla mucho más sobre ella, y describe episodios en los que interactúa con su marido, sus hijos, su aya, su camarera y algunas mujeres de su casa; pero la narración se centra en los años más cercanos a la fecha de su muerte ${ }^{23}$.

Paralelamente, y pese a que prácticamente no existen en los libros de la cancillería de João I documentos otorgados por ella, sí se conservan algunos originales, y algunas copias, de testimonios de este tipo en compilaciones documentales reunidas por los concejos. Entre ellos, además de los que muestran claramente que la mano de Felipa de Lancáster estuvo implicada en su elaboración, encontramos -afortunadamente- bastantes en los que João I asocia a su nombre, como autor de la carta o diploma, el de su mujer; y, a veces, también los de alguno o algunos de sus hijos, como lo hicieron algunos de sus predecesores y parecía ser habitual en otros reinos de la Península Ibérica. Ello permite que hablemos, de nuevo, de una monarquía compartida por los diversos miembros de la familia real; entre los que destacan el rey y la reina ${ }^{24}$. Junto con estas cartas -cerca de ochenta- del rey y de la reina, existen otras pruebas documentales del papel ejercido por Felipa dentro de su familia, y en especial de su capacidad para desempeñar las tareas que le competían. A partir de todo ello, presentaremos en este texto a Felipa como modelo de reginalidad en Portugal en la Edad Media.

${ }^{19}$ Parsons 1998, p. 2.

${ }^{20}$ Woodacre 2013,p. 1.

${ }^{21}$ Duggan 1997, p. XXI.

${ }^{22}$ Lopes 1983.

${ }^{23}$ Zurara 1985.

${ }^{24}$ Silva 2014, p. 210. 


\section{2. ¿QUIÉN ERA FELIPA DE LANCÁSTER, LA ÚNICA INGLESA QUE FUE REINA DE PORTUGAL?}

Felipa de Lancáster debió llegar a la Península Ibérica, y desembarcado en La Coruña, a fines del mes de julio de 1386, junto con gran parte de su familia. A pesar de ser nieta, por el lado paterno, del rey Eduardo III de Inglaterra -y prima directa del rey Ricardo II, titular del trono en ese momento-, los títulos que su padre ostentaba, y entre los que destacaba el de duque de Lancáster, se asociaban a territorios heredados del abuelo materno de Felipa ${ }^{25}$. Blanca de Lancáster, madre de Felipa, murió probablemente en 1368; y en 1371 -como ya se indicó- Juan de Gante había contraído de nuevo matrimonio en Aquitania, llevando después a Inglaterra una madrastra castellana para Felipa y sus hermanos, Elizabeth y Henry ${ }^{26}$.

Parece que, cuando se casó con el duque de Lancáster, Constanza era ya la mayor de las hijas vivas del rey Pedro I de Castilla, que había sido asesinado en 1369 por su medio hermano Enrique, conde de Trastámara. Antes, a lo largo de la guerra civil que precedió al regicidio, el hermano mayor de Juan de Gante, Eduardo, príncipe de Gales y de Aquitania, había apoyado militarmente al rey Pedro siguiendo las órdenes de su padre. Cuando Eduardo enfermó y regresó a Inglaterra, Juan quedó al frente de Aquitania ${ }^{27}$. Tanto el enlace de Juan con Constanza como el de su hermano Edmund, conde de Cambridge, con la otra hija del rey Pedro, Isabel, situaban a los hijos del rey de Inglaterra del lado de los partidarios del monarca asesinado; y, por consiguiente, en contra del nuevo rey castellano, Enrique II. Ambas, Constanza e Isabel, eran consideradas las herederas directas del rey don Pedro; y por ello Juan y Constanza se titularon reyes de Castilla y León. Con todo, sólo catorce años más tarde, y reinando ya en Inglaterra Ricardo II, se puso en marcha un verdadero plan de conquista de Castilla.

A principios del mes de julio del año 1386, acompañados de un ejército, y de las tres hijas legítimas del duque, Juan y Constanza embarcaron en Plymouth. Sabían que en la Península podían contar con un aliado: el rey de Portugal, João I, recientemente aclamado, acababa de vencer a su homónimo castellano, el hijo y heredero de Enrique II, en la batalla de Aljubarrota. La existencia de un enemigo común había llevado a que Portugal e Inglaterra firmasen en Windsor una alianza en el mes de mayo, poco antes de que la flota partiese. Por ello no sorprende que el duque y su esposa, tras desembarcar en

${ }^{25}$ Ibidem, pp. 33-36.

${ }^{26}$ Ibidem, pp. 60-76.

${ }^{27}$ Russell 2000, p. 194. 
La Coruña y tomar -encontrando poca resistencia- varias plazas gallegas, se apresurasen a contactar con Juan de Castilla, para que se rindiese y les entregase el trono, y con João de Portugal, para que ratificase el Tratado de Windsor y llevase adelante las medidas necesarias para materializar lo acordado. Entre los acuerdos debía encontrarse el enlace entre la hija primogénita del primer matrimonio del duque, Felipa, y el rey de Portugal, soltero e incapacitado aún para casarse por haber sido maestre de la Orden Militar de Avis antes de ocupar el trono ${ }^{28}$.

\section{LAS REGENCIAS EN NOMBRE DE SU MARIDO}

Las bodas de Felipa de Lancáster y João I de Portugal se celebraron en Oporto en el mes de febrero del año 1387. Tras la ceremonia religiosa, el día 2, el rey convocó a los procuradores de los concejos, y a los representantes de la nobleza y del clero, para que se sumasen a los festejos a partir del día 14 . João I pretendía tomar casa y, para ello, y para preparar la incursión que iba a hacer en Castilla acompañando a su suegro, debía reunir Cortes $^{29}$. De este modo, la ciudad de Oporto se llenó de gentes que participaron en las celebraciones de la boda real. Entre ellos, según el relato del cronista Fernão Lopes, no estaban el padre y la madrastra de Felipa. Aguardaban, en los alrededores de Bragança, a que llegase el ejército de su yerno para, uniendo los dos contingentes, entrar juntos en tierras castellanas. Así, cuando apenas llevaba un mes casada, la nueva reina de Portugal hubo de desplazarse a Bragança para despedirse de su familia. Desde allí se encaminó al sur, y durante algún tiempo se estableció en Coímbra. Probablemente su séquito era grande pues, aparte de varios hidalgos, la acompañaba el arzobispo de Braga.

De hecho, ya se había convocado una nueva reunión de Cortes, destinada a la aprobación de las nuevas fuentes de ingresos, que sería presidida por la propia Felipa, asistida por doutores e prelados e a casa dos desembarguadores do Reino ${ }^{30}$. En esas Cortes se decidiría lanzar sisas generales durante un periodo de un año -del 1 de junio de ese año al 1 de junio del siguiente- $y$ se redactaría un documento que contendría los once artículos que regulaban su recaudación. Probablemente, habiendo sido esta reunión la continuación de la celebrada en febrero en Oporto, se emitieron en ella confirmaciones de los capítulos resueltos en aquella ocasión ${ }^{31}$.

${ }^{28}$ Silva 2014, pp. 95-116.

${ }^{29}$ Sousa 1990, p. 295.

${ }^{30}$ Lopes 1983, vol. II, p. 228.

${ }^{31}$ Rodrigues 1981, vol. VI, p. 400; Sousa 1990, vol. I, p. 296. 
Aunque se tratase oficialmente de la conclusión de la reunión anterior, la presidencia de estas Cortes por la reina Felipa muestra que existía una cierta concepción del poder de la esposa del rey. Felipa de Lancáster por entonces seguramente no sabría aún hablar portugués, aunque quizá sí tuviese algunas nociones de castellano gracias al contacto con su madrastra y su séquito; y la convivencia con el rey, su marido, aún no se había prolongado lo suficiente como para que éste pudiese evaluar sus capacidades políticas. Sin embargo, João I no dudó en colocarla al frente del gobierno apenas un mes después de haberse casado con ella.

Tras esta primera ocasión, y con motivo de la guerra con el reino vecino, debió haber otras en las que Felipa asumió ese papel. A fines de 1397, por ejemplo, cuando se reavivaron los conflictos fronterizos y, de nuevo, el rey de Portugal -esta vez ya sabiendo que podía delegar en ella responsabilidades gubernativas- dejó a Felipa en Santarém, y acompañada por algunos oficiales, a cargo del reino y con amplios poderes:

E porem uos mandamos que façades todo aquello que uos per ella ou per ssuas cartas e aluaraes for mandado. E esso meesmho per nossas ccartas assynadas per os do nosso dessenbargo que com ella ffica E asseeladas com o Sello da dicta Senhor<a $>$ assy como se nos mesmho uo llo mandassemos.

Outrossy por esta carta mandamos ao <noso $>$ Thesoureiro moor E a todollos nossos almoxarifes $\mathrm{E}$ Reçebedores $\mathrm{E}$ escriuães das nossas Rendas E dereitos E a qualquer delles que por nossas cartas assynadas per a dicta Senhora ou per aluaro perez a que leixamos encarrego do dessenbargo da fazenda E asseeladas com o dicto sseu Seello dem E paguem quaeesquer dinheiros E panos E ouro E prata e armas e almazem $E$ pam $E$ todalas outras cousas que lhes per essas cartas ffor mandado Segundo em ellas for conthudo. E cobrem essas cartas E estromentos de conheçimento de como fezerem os dictos pagamentos.

$\mathrm{E}$ mandamos aos nossos contadores $\mathrm{E}$ a outros quaaesquer que esto ouberem de beer que lho Reçebam em conta e despesa sem outra contenda nemhũa $E$ que façom logo Registar esta carta no liuro dos contos pera nom sseer posta dobida aaquelles que os dictos pagamentos fezerem ${ }^{32}$.

\section{LA MONARQUÍA COMPARTIDA}

Al estudiar el papel desempeñado por la reina Leonor Teles, mujer del rey Fernando y antecesora de Felipa en la corte portuguesa, Isabel de Pina Baleiras constató que su esposo llamó con alguna frecuencia a la citada reina

${ }^{32}$ AN-TT, Ch.P.D. João I, L ${ }^{\circ}$ 5, f. 35 (1435) 1397, Évora, 27 de Outubro. 
para que firmase con él, o al menos figurase, en algunas de las cartas de donación, destinadas a individuos o instituciones religiosas, que concedió. Según esta autora,

el rey pretendía compartir con la reina, y tener su aval y participación, en las mercedes y gracias concedidas a las más altas esferas del reino porque formaba parte de su equipo, no estaba por debajo ni por encima de él sino a su lado, dado que -según la legislación- tenía parte do regimento do Regno, e do Estado, que nos DEOS deu ${ }^{33}$.

João I, esposo de Felipa de Lancáster, siguió una política semejante. El 6 de enero de 1388 recuperó una vieja fórmula, utilizada por los tempranos monarcas de la primera dinastía ${ }^{34}$, al otorgar privilegios a su antigua orden religiosa de caballería, la de Avis, em sembra com a Rainha dona Filipa mjnha mujer $^{35}$. Meses más tarde, a fines de abril, la misma fórmula le permitía recompensar a don Pedro de Castro, yerno de João Afonso Telo, con el señorío de Cadaval, que perteneciera al último ${ }^{36}$. El 2 de febrero de 1389 utilizaba una expresión menos arcaica -juntamente com mjnha molher-para asociar su nombre al de la reina - filha do muj nobre dom Joham ducque d alancastreen una carta firmada también por ambos ${ }^{37}$. Antes de ello, el 2 de diciembre de 1388, un privilegio concedido en Évora al maestre de la Orden de Avis había contado asimismo con ambas firmas ${ }^{38}$.

El 7 de diciembre de 1390 la pareja real, que había sido bendecida con un hijo varón, Alfonso, nacido en junio o julio de ese año, asociaba al casi recién nacido a su decisión de conceder al obispo de Coímbra, D. Martinho, el patronato de la iglesia de São Cristóvão, en Lisboa, en donde dicho obispo pensaba instituir una capilla funeraria. La fórmula utilizada -Dom Joham pella graça de deus Rey de portugal e do algarue ensembra com a Raynha dona Filipa e com dom afomso Nosso filho primogénito e herdei$r o^{39}$ - se repetiría en otros diplomas en los años siguientes. Por ejemplo, en el diploma emitido en 1391, cuando Alfonso contaba un año de edad, a favor de D. João, obispo de Oporto, que también pretendía fundar una capilla para depositar en ella los restos de sus familiares en una iglesia lisboeta, en este

\footnotetext{
${ }_{33}^{33}$ Baleiras S. Campos 2008, pp. 107-108; Ordenações Afonsinas, Livro II, tít.63, $15^{\circ}$ item, p. 404 , lei de $13 / 09 / 1375$.

${ }^{34}$ Benevides 2007, pp. 5-6.

${ }^{35}$ Ch.P.D. João I, vol. II, T.I, [II-109], p. 63.

${ }^{36}$ Ch.P.D. João I, vol. II, T.I, [II-333], pp. 182-183; Silva 2004.

${ }^{37}$ Ch.P.D. João I, vol. II, T.I, [II-106], p. 61.

${ }^{38}$ Ch.P.D. João I, vol. II, T.I, [II-367], pp. 199-200.

${ }^{39}$ Ch.P.D. João I, vol. II, T.I, [II-498] p. 262.
} 
caso la de São Salvador. El rey accedió a este último pedido con especial placer, pues quien lo solicitaba había sido embajador en la corte de Roma en dos ocasiones especialmente delicadas, duas vezes poendo seu corpo em auentura $^{40}$.

Al estudiar los documentos emitidos por los fundadores de la dinastía Avis parece quedar claro que la participación en los poderes regios, a la hora de conceder gracias y mercedes a los vasallos de la Corona, no se limitaba a la esposa del rey. La asociación del heredero a las decisiones conjuntas de los monarcas, además de subrayar su legitimidad, muestra que dichas decisiones se concebían como irrevocables y se quería que fuesen definitivas. Es decir, había -o, al menos, todo parece demostrar que había- determinadas materias de gobierno en las que no bastaba con el aval del rey, sino que era necesario contar también con los de los que compartían con él la governança. Ello era reconocido también por instancias internacionales como la Santa Sede, que dirigía sus bulas conjuntamente al rey y a la reina ${ }^{41}$.

Los beneficiarios de las concesiones regias eran personas muy próximas al monarca o a la reina. En ocasiones los procesos eran delicados, porque muchas veces se donaban bienes que antes habían pertenecido a individuos que habían dejado de apoyar al rey. En 1397 el doctor en leyes João das Regras, a quien João I en buena medida debía su aclamación, recibió el realengo de Oeiras, que pudo sumar a su señorío en Cascais, y que antes había estado en poder del conde D. Henrique, que se partiu de nos e se fora pêra o dicto nosso auersairo e nos desserujra ${ }^{42}$. En 1398, tras haberse reanudado las hostilidades con Castilla -en donde ahora reinaba Enrique III, casado con una medio hermana de Felipa-, hubo varias dolorosas deserciones de algunos de los vasallos más próximos al rey que conllevaron pérdidas territoriales ${ }^{43}$. Ese año, moviéndose entre Oporto y la frontera del río Miño, João I llevó a cabo una serie de expropiaciones de tierras de traidores, y una serie de entregas de estas propiedades a sus fieles en calidad de recompensa por su lealtad. El 10 de abril, por ejemplo, explicó que pollas maldades e treições que Joham ferrnandez Pacheco cometeo contra a nossa pesoa e contra nossos regnos em contractar com el rrey de castella nosso Jmigo, y por haber prometido entregar al monarca castellano algunos lugares del reino de Portugal, tenía derecho a confiscar los bienes muebles y de raíz que dicho João Fernandes Pacheco poseía, y a entregárselos a Gonçalo Peres, miembro de su consejo. Com acordo

${ }^{40}$ Ch.P.D. João I, vol. II, T.I, [II-405], p. 216.

${ }^{41}$ Monumenta Henricina 1960, vol. I, docs. 113, 118, 128, pp. 263-264, 275-276, 306-309.

${ }^{42}$ Ch.P.D. João I, vol. II, T. III [II-1219], pp. 95-96.

${ }^{43}$ Coelho 2005, pp. 107-109. 
e consentimento de la reina Felipa y del infante primogénito, claro ${ }^{44}$. Todas las restantes propiedades de João Fernandes Pacheco tuvieron el mismo destino, y con ello contribuyeron a mejorar el nivel de vida de otros partidarios del monarca. Lo mismo ocurrió con los bienes de otros traidores, como Egas Coelho ${ }^{45}$ y João Afonso Pimentel ${ }^{46}$.

En el año 1400 el rey seguía sufriendo bajas entre sus vasallos. Álvaro Coitado se exilió en Castilla, y João I no se lo perdonó. Sus bienes pasaron a proporcionar un buen modo de comenzar una vida autónoma a Gonçalo Vasques de Melo o Moço, que se había criado en la corte y formaba parte de una familia a la que el rey debía agradecer varios servicios ${ }^{47}$. También se transformaron en mercedes concedidas a miembros del consejo real y a personajes de alta estirpe al servicio del rey o de la reina ${ }^{48}$.

Desde -al menos- 1396 el primogénito Alfonso ya sabía firmar las cartas regias que eran emitidas con su consentimiento, o de las que era coautor ${ }^{49}$; pero murió en Braga a fines de 1400, contando apenas diez años, y por ello a partir del 12 de abril de 1401 fue el segundo hijo de Felipa, Duarte, el que pasó a compartir con su padre y con su madre la autoría de cerca de treinta y cinco cartas de gracia, desde entonces y hasta 1415, año de la muerte de Felipa $^{50}$.

Esta coparticipación en las responsabilidades regias deriva, como fácilmente puede deducirse, de una concepción patrimonial del reino según la cual competía a toda la familia real ejercer como vigilantes de los bienes que sustentaban su especial estatuto; pero el significado de este reparto del poder parece no haberse ceñido exclusivamente a los aspectos materiales. Como ya se ha señalado, la introducción de las firmas de la reina y del príncipe heredero en los documentos, junto con la inclusión de las firmas de los más poderosos validos, garantizaban que dichos documentos tuviesen una cierta perpetuidad. Una prueba de que se consideraba importante que estas autorizaciones fuesen firmadas y aprobadas por un grupo amplio de personas se encuentra en la carta regia de privilegio emitida el 24 de agosto de 1415 -poco después de la muerte de la reina Felipa - y dirigida a Gonçalo Vasques Coutinho, que se encontraba en Ceuta. El rey anuncia en ella que contiene o outorgamento do meu filho ho

\footnotetext{
${ }^{44}$ Ch.P.D. João I, vol. II, T. III [II-1138], pp. 55-56.

${ }^{45}$ Ch.P.D. Duarte, vol. I, T. I [447], p. 216.

${ }^{46}$ Ch.P.D. Duarte, vol. I, T. II [999], pp. 263-264; Ch.P.D. João I, vol. II, T. III [II-1143], p. 60 .

${ }^{47}$ Ch.P.D. João I, vol. II, T. III [II-1336], p. 161.

${ }^{48}$ Ch.P.D. João I, vol. III, T. I [I-164], p. 75; Ch.P.D. João I, vol. II, T. III [II-1439], p. 199; Ch.P.D. Duarte, vol. I, T.I [308], pp. 168-169.

${ }^{49}$ Ch.P.D. João I, vol. II, T. II [II-998], pp. 205-206. Su aval aparece en unas 30 cartas.

${ }^{50}$ Ch.P.D. João I, vol. II, T. III [II-1439], p. 26.
} 
Jffante eduarte primogenjto e herdeyro e o conselho de meus filhos o Jffante dom Pedro e o Jffante dom anrrique ${ }^{51}$.

\section{EL PAPEL DIPLOMÁTICO EN LA SOMBRA}

\subsection{Portugal y Castilla}

Como mencionamos al inicio de este ensayo, siendo normalmente oriundas de naciones extranjeras, las reinas eran también, no pocas veces, las encargadas de las negociaciones delicadas, ya fuese con sus reinos de origen -en cuyo caso sus interlocutores solían ser parientes suyos-, ya con otros gobernados también por miembros de su familia. El papel de las reinas se mantenía así en la esfera familiar privada, pero tenía repercusiones políticas de gran importancia; cuyo mérito raramente se les atribuía por quedar oculto en la compleja red que formaban las relaciones diplomáticas. Así, las sucesivas treguas y la posterior firma de las paces entre Portugal y Castilla debió mucho a los esfuerzos de la medio hermana de Felipa, Catalina de Lancáster, como reconoce el cronista Fernão Lopes: esta Rainha dona Caterina, semdo seu marido vivo, trabalhava muito com elle que ouvese boa paaz e amizade com dom Joham Rey de Purtuguall, casado com sua irmãa ${ }^{52}$.

Aunque no hay indicios de ninguna acción individual directa por parte de Felipa en ello, puede suponerse que las iniciativas tomadas por la reina de Castilla -regente durante la minoría de edad de su hijo- fueron muchas veces concertadas con Felipa a través de una correspondencia que no se ha conservado. De hecho, y como subraya Ana Echevarría, biógrafa de Catalina, el vínculo familiar de ésta con la familia real portuguesa es uno de los aspectos más destacables de la comunicación diplomática entre los dos reinos ${ }^{53}$; lo que llevó a César Olivera Serrano a considerar que Catalina mantenía una posición coherente con los intereses de su familia de sangre, pero no con los de su marido o sus hijos ${ }^{54}$. De hecho, Castilla y otros reinos continuaban considerando a la nueva familia reinante de Portugal como usurpadora.

Fernão Lopes afirma que, en vida de su marido, Catalina intentó convencerlo para que desistiese de sus ambiciones sobre Portugal, dado que esas aspiraciones se sustentaban en bases frágiles y legalmente poco seguras ${ }^{55}$. Sin

${ }^{51}$ Ch.P.D. João I, vol. III, T. III [III-932], p. 85.

${ }^{52}$ Lopes 1983, vol. II, p. 412.

${ }^{53}$ Echevarría 2002, p. 179.

${ }^{54}$ Olivera-Serrano 2005, p. 130

${ }^{55}$ Lopes 1983, vol. II, p. 412. 
embargo, el alcance de una paz duradera entre ambos reinos se dilataba debido a las exigencias de ambas partes. Castilla exigía a Portugal compensaciones por los daños sufridos durante la guerra, al igual que Portugal se las exigía a Castilla; pero, además, pretendía que los nobles portugueses que se habían aliado a los castellanos recibiesen indemnizaciones por los bienes que les habían sido expropiados. Quería también que cierto número de navíos de la flota portuguesa se vinculase de manera permanente a Castilla, que entretanto había iniciado una guerra con Granada. Todo ello hizo que las negociaciones de paz se prolongasen hasta el año 1411, a pesar de que Catalina venía manteniendo las conversaciones desde 1408. La intención de la reina de Castilla era, claramente, encontrar una solución al conflicto; pues desde la muerte de su esposo Enrique III -en 1406- compartía tanto la regencia como la tutela de su hijo Juan II con su cuñado Fernando, y el rey de Portugal venía mostrando durante todo ese tiempo que estaba de su lado ${ }^{56}$.

En realidad, los dos regentes estaban interesados en llegar a un entendimiento con João I de Portugal, pues ello también favorecería los objetivos que Fernando tenía en mente. Uno de ellos era la campaña militar contra el reino de Granada, que concebía como decisiva, y en la que pretendía contar con el apoyo naval portugués, como acabamos de indicar. El otro empezó a tomar forma en 1409, cuando murió prematuramente el heredero al trono aragonés, y se definió el año siguiente, cuando lo hizo el rey Martín I. Teniendo lazos familiares con la dinastía reinante en Aragón, heredados de su madre, Fernando se presentaba como un fuerte candidato al trono; aunque se le oponían otros pretendientes. Le convenía, por ello, que cesasen las hostilidades con Portugal. Incluso podía concebir que llegase a convertirse en su aliado ${ }^{57}$. Por todo ello, no debe haber sido particularmente difícil para Catalina asumir la dirección de las negociaciones con Portugal; ni ejercer como mediadora entre João I, por un lado, y el consejo real castellano, junto con el infante don Fernando, por el otro ${ }^{58}$.

Las crónicas de Fernão Lopes y Gomes Eanes de Zurara son las principales fuentes para la historia del proceso de paz, y en ellas se destaca el gran empeño mostrado por la reina castellana para conseguir pacificar las relaciones entre su reino y el de su hermana y su cuñado ${ }^{59}$. En las cartas

\footnotetext{
${ }^{56}$ Ibidem, vol. II, p. 437.

${ }^{57}$ Zurara 1985, p. 21.

${ }^{58}$ Valdeón Baruque 2001, p. 175; "temdo desto esperto sentido, trabalhou de tall guissa que o Ifamte dom Fernamdo tio del Rey e todollos gramdes do Regno do Conselho de seu filho leixaram encarguo a ella que falase no trauto da paz e iguoaldase quoaesquer cousas que a ella pertemcesem", Lopes 1983, vol. II, p. 422.

59 "A Rainha dona Caterina que muito desejava paaz e aseseguo amtre Purtuguall e Casteella”, ibidem, vol. II, p. 422.
} 
transcritas por Fernão Lopes quedan registradas muestras de afecto entre las dos familias:

Muy cara e mui amada a que com todo nosso coraçaom mui inteiramente bem queremos, irmaã amigua Rainha de casteella e de Leom. Nos, el Rex de Purtugall e do Alguarve, vos imviamos muito saudar, como a irmaã e amiga que muito amamos e prezamos e pera que queríamos que Deos dese tanta saúde e vida e homrra como vos mesmo desejaes ${ }^{60}$.

Los relatos también registran los protocolos reservados a los parientes reales. Describen, por ejemplo, una de las embajadas enviadas a Castilla por los reyes de Portugal, recibida con mucha honra por la regente y sus hijos, a los que les fueron entregados regalos enviados por los infantes portugueses para sus primas, hermanas del rey, y para la esposa y los hijos de don Fernando, antes de la ceremonia del besamanos ${ }^{61}$.

Pese a todo ello, alcanzar la paz no era tarea fácil. João I se quejaba de que en todos los encuentros le habían sido requeridas tam desvairadas e desiguoaaes cousas que nunca se habían dado las condiciones para avanzar hacia el entendimiento entre ambas partes. Proponía, por ello, que la firma de las paces no estuviese condicionada por cláusulas que no podía aceptar. Esa paz boa e simples que pretendía se logró cediendo. El rey de Portugal se mantuvo firme en el rechazo a verse obligado a enviar diez galeras y hombres armados en apoyo de cualquier campaña castellana contra Granada. También consiguió que de las compensaciones a los portugueses que habían abandonado el reino por las expropiaciones llevadas a cabo - una de las materias más delicadas- se excluyese a los que lo habían hecho en el periodo más complejo -entre 1383 y 1396-, y que los gobernantes de Castilla hiciesen lo mismo en relación a los castellanos que se habían exiliado en Portugal ${ }^{62}$. Con todo, inmediatamente después de que se firmase la paz entre los dos reinos, la reina de Castilla solicitó ayuda en la guerra contra Granada:

Esto, mui caro e mui amado irmão, screpvo porque Deos sabe que desta cousa ei gramde comsolaçã e sam mui leda e emtemdo isso mesmo que vos e a Rainha vosa molher, minha mui amada e prezada irmã, serees per a Deos prazer por esta paaz, e eu emtemdo que pera ella lhe comprira e hee muito necesario aver de vos ajuda de dez ou doze gales ${ }^{63}$.

\footnotetext{
${ }^{60}$ Ibidem, vol. II, p. 426.

${ }^{61}$ Ibidem, vol. II, p. 430.

${ }^{62}$ Zurara 1985, p. 22.

${ }^{63}$ Lopes 1983, vol. II, p. 442: "escrevo-vos sobre esta matéria porque Deus sabe como estou feliz e aliviada e sei que também vós e a vossa mulher, minha muito amada e prezada irmã,
} 
Y, sin existir obligaciones dictadas por tratados, el rey de Portugal garantizó su apoyo ${ }^{64}$.

Como era habitual, tras la firma de las paces se llevaron a cabo negociaciones destinadas a reforzar los lazos de sangre entre ambas casas por la vía matrimonial. Según nos cuenta Fernão Lopes, el rey João I de Portugal tenía la intención de iniciar conversaciones con el infante don Fernando para pactar uniones entres varios de sus hijos; pero la reina Catalina indicó a su cuñado que nos casamentos nã se tremetese ${ }^{65}$. Tenía en mente casar a su hija homónima con el heredero del trono de Portugal, y concertó un encuentro con su medio hermana Felipa para ponerse de acuerdo en lo referente a ése y otros enlaces. Dicho encuentro no llegó a tener lugar por razones que se desconocen. Ana Echevarría cree que dichas razones estaban relacionadas con problemas de salud de Catalina ${ }^{66}$. Consta que a Duarte, el heredero portugués, no le agradó el plan de casarse con una niña que por entonces contaba apenas ocho años, doce menos que él. Quizá por ello, los reyes portugueses hicieron una contrapropuesta: casar a su única hija, Isabel, de catorce años, con Juan II, que por entonces tenía seis ${ }^{67}$. Años más tarde el propio Juan escogería casarse con su prima María, hija de su tío Fernando, y por entonces ya infanta de Aragón ${ }^{68}$; con lo que el principal objetivo de Catalina de Lancáster, esto es, afianzar y potenciar los lazos de sangre con Portugal, no se vio cumplido antes de su muerte, en $1418^{69}$.

\subsection{Portugal y Aragón}

La firma de las paces entre Portugal y Castilla en 1411 no hizo que disminuyese la desconfianza que los reinos cristianos ibéricos mostraban unos hacia otros. Portugal se concentró desde ese momento en la preparación de una campaña militar dirigida a Ceuta, y ello exigió tales movimientos e inversiones que no pasó desapercibido para los otros monarcas de la Península. Los

também agradeceis a Deus por esta paz, e eu entendo que para que [esta campanha] se cumprir é muito necessário ter a vossa ajuda de dez ou doze galés".

${ }^{64} \mathrm{Ibidem}$, vol. II, p. 443. Tal y como ya había prometido en un mensaje enviado a la reina de Castilla: "visto os grandes esforços e boos dividos que amtre el Rey e Rainha nosos Senhores e vós e seus filhos e os vosos, a isto soo o uoso emtemder he abastamte certidam e comfiamça pera vos el Rey noso Senhor fazer quoallquer ajuda, quando lhe por vos parte fose requerida, sem avemdo hi mais obriguação de trauto", ibidem, vol. II, p. 436.

${ }^{65}$ Ibidem, vol. II, p. 445.

${ }^{66}$ Echevarría 2002,p. 179.

${ }^{67}$ Lopes 1983, vol. II, p. 446.

${ }^{68}$ Rodrigues 2008, p. 219.

${ }^{69}$ Echevarría 2002, pp.171, 174, 179. 
genoveses que vivían en Lisboa habían hecho correr el rumor de que la ciudad de Sevilla era el objetivo del ataque portugués. Ese rumor llegó por carta a Castilla, al consejo real y a la reina regente; y se exigió que el rey de Portugal enviase una delegación para que en su nombre jurase que era infundado ${ }^{70}$. Pero, después de que Castilla se asegurase de que la campaña naval no iba dirigida contra ellos, fue Aragón quien comenzó a sentirse inseguro.

Habiendo accedido al trono de Aragón poco antes, Fernando I no tenía dudas de que sus opositores aún contemplaban arrebatárselo; y algunas de las teorías acerca del destino de la armada portuguesa apuntaban a Sicilia, que se encontraba dentro de la órbita de intereses aragoneses. A los embajadores enviados João I les respondió lo siguiente: vós direis (...) a El-Rei D. Fernando, meu amigo, depois de apresentardes as minhas saudações, que ele saiba de forma segura que os meus preparativos não são contra ele, nem contra nada do que lhe pertence $e^{71}$.

Aun así, Felipa se sintió en la obligación de escribir también al rey de Aragón, a quien se dirigió como muy amado e muj preçado rrey d Aragom, sobrinho amigo. En su mensaje dejó bien claro que había visto la carta de la que sus enviados habían sido portadores, y que había asistido a la audiencia que su marido les concediera -per o que elles da uossa parte diserom, foy certa do que deseiauades saber-. Hacía también referencia a la carta con la que João I había respondido al monarca aragonés. Sabiendo que su marido le daba en ella todo tipo de explicaciones en relación a la materia en causa, Felipa se limitaba a tranquilizar a su "sobrino" diciéndole que nunca había sido su intención causar cualquier tipo de daño a su territorio o patrimonio, y ofreciéndole cualquier tipo de ayuda portuguesa que pudiese serle de utilidad. La despedida era calurosa: Deus, por sua merçee, uos tenha em sua guarda e me enuje sempre de uos boas nouas ${ }^{72}$.

\subsection{Portugal y Granada}

Cuando aún luchaba por el trono de Aragón, el por entonces regente de Castilla, Fernando de Antequera, firmó unas treguas con Granada y, con ello, hizo que se descartase la posibilidad de que João I de Portugal dirigiese un ataque contra el reino nazarí ibérico ${ }^{73}$. Sin embargo, en 1411 el monarca nazarí envió a Portugal una gran embajada pidiendo garantías de que no sería

${ }^{70}$ Zurara 1985,pp. 71-73.

${ }^{71}$ Ibidem, p. 75.

${ }^{72}$ Monumenta Henricina 1960, vol. II, pp. 121-122.

${ }^{73}$ Zurara 1985, p. 24. 
objeto de una expedición militar ${ }^{74}$. El rey la recibió en audiencia y aseguró que no pretendía conquistar ese reino. Los enviados, no del todo convencidos, trataron de obtener de la reina más informaciones. Formaba parte de la embajada a rica forra, que era a principal das mulheres do Rei Mouro -según narra el cronista Gomes Eanes de Zurara-, quien pidió entrevistarse con Felipa, explicando que solo así conseguiría cumplir la misión que se le había encomendado. En el discurso dirigido a la reina argumentó que porquanto ela sabia quanto os bons pedidos das mulheres tocam os corações dos maridos, quando lhes pedem algumas coisas que desejam, le rogaba que consiguiese que su marido diese a los embajadores una respuesta definitiva sobre el asunto que les había llevado a Portugal. Le prometía a cambio compensaciones, pois que ela tinha uma filha para casar em breve tempo poderia ver o agradecimento pela sua boa vontade, pois lhe garantia enviar-lhe o melhor e mais rico enxoval que nunca fora dado a nenhuma princesa moura ou cristã. Felipa, firme en la idea de no interferir en los asuntos político-militares de su esposo, le respondió marcando con firmeza las diferencias existentes entre ella -reina cristiana- y su interlocutora. El cronista, atónito con la violencia de la respuesta de la serenísima reina, explica que era uma mulher muito amiga de Deus (...) natural de Inglaterra, nação que é a que entre todas, mais odeia todos os infiéis, entendiendo que ello justificaba el tono utilizado en la réplica.

Eu não sei, respondeu ela, o modo como os vossos reis se comportam com as suas mulheres, porém, entre os cristãos, não se considera bem que alguma rainha ou princesa se intrometa nos feitos de seu marido, pois que, em tais casos eles têm os seus conselhos onde resolvem os feitos como entendem e as mulheres são tanto melhores quanto maior diligência se abstém de tentar saber o que não lhes compete, pois conhecem seguramente que os seus maridos com seus conselheiros têm maior cuidado sobre o que convém à honra do seu estado, do que o que elas podem conhecer.

Así -concluía Felipa- las reinas conseguían que sus deseos fuesen siempre atendidos, pues os pedidos são tais que os maridos não têm motivo para lhos negar. Las que así no lo hacían não são havidas por bem educadas $e$ discretas. Para dar por finalizado el encuentro, Felipa rechazaba la oferta del rey de Granada -com a graça de Deus, à minha filha não faltará enxoval para o seu casamento- y recomendaba a su enviada que, si lo consideraba oportuno, se dirigiese directamente a João I solicitándole las informaciones que requería: se vós lhe solicitardes o que é justo, ele concordará com muito

\footnotetext{
${ }^{74}$ Ibidem, p. 78.
} 
boa vontade ${ }^{75}$. En suma, y siempre según el cronista, Felipa no se consideraba una instancia de recurso. Afirmaba que no interferiría en los negocios del reino que otros, mucho mejor que ella, estaban capacitados para resolver. Ello, en todo caso, parece que no le impidió inmiscuirse en materias de índole política -sobre todo relacionadas con Inglaterra- en las que consideró que su intervención sí tenía cabida.

\subsection{Portugal e Inglaterra}

Desde el año 1940 se conocen cuatro cartas escritas por Felipa de Lancáster y destinadas a figuras destacadas de la sociedad inglesa, familiares suyos. También una epístola que le fue enviada por un pariente en un momento especialmente complejo de la historia de Inglaterra. Todas ellas fueron publicadas en los apéndices de la comunicación presentada en el Congresso do Mundo Português por W. J. Entwistle y P. E. Russell, titulada A Rainha D. Felipa e a sua Côrte $e^{76}$.

Curiosamente, no existen vestigios de correspondencia entre el duque de Lancáster y Felipa ${ }^{77}$.

En la correspondencia de Felipa se detecta, en tiempos de Ricardo II, un gran empeño en preguntar por aquellos que, tras haber prestado servicios al rey de Portugal, habían regresado a su reino de origen. Tal fue el caso de Adam Davenport, quien llegó a la Península como capellán de los Lancáster y permaneció en ella ocho o nueve años, desempeñando las funciones de capellán de la reina. Apoyando su "natural inclinación" a regresar a su tierra natal para pasar allí sus últimos días ${ }^{78}$, y sabiendo que cuando llegase no contaría con ingresos para mantenerse, la reina le pedía a su primo que le concediese "beneficios" $"$, añadiendo que con ello le haría mucha honra y le proporcionaría gran placer.

Felipa se dirigía a Ricardo II de forma cortés y delicada, pero no por ello dejaba de insinuar la intimidad de sus relaciones, ya fuese mostrándose

\footnotetext{
${ }^{75}$ Ibidem, pp. 78-80.

${ }^{76}$ Entwistle, Russell 1940, pp. 339-346.

${ }^{77}$ Russell 2000, p. 581.

${ }^{78}$ Legge 1941, [28], pp. 73-74: "nien meins come chescun esteant hors de son propre paijs de naturelle inclination, desire de resorter a ycelle, il ad tresgrand desir (...) de fere ses darreins jours en vostre tresnoble terre d'Engleterre".

${ }^{79}$ Ibidem, "vous supplie, mon tresgracieux seigneur, le plus effectuelment que je saye ou puisse que mon dit clerc veuilliéz avoir especialment recommendéz et de vostre bonteuouse noblesse lui doner le premiere benefice que apartiendra a vostre donison convenable pour son estat, parmy quel el pourra le plus honurablement soy meinteigner".
} 
deseosa de que le contase novedades ${ }^{80}$, ya dando noticias de su familia, que creía serían recibidas con satisfacción por su primo. Le informaba, por ejemplo, de que en la fecha de envío de la carta su marido y sus cuatro hijos se encontraban bien de salud.

Años más tarde, en 1403, habiendo sido destituido Ricardo II y elevado a la dignidad regia su primo Enrique IV, hermano de la reina Felipa, el rey João I de Portugal se dirigía al último llamándole Muitalto, muy nobre, e muy excelente e poderoso Principe, nosso muy amado e muy preçado irmaão e amigo, Rey d'Ingraterra, de França, e Senhor d'Irlanda. En esa carta le saludaba - de todo corazón- como a hermano y amigo a quien muy verdaderamente amaba y apreciaba sobre todos los Principes do mundo, y le deseaba que Dios le diese una larga vida y salud, y una gran exaltación de su honra. A continuación le invitaba a certificar el consentimiento de las treguas entretanto firmadas por Portugal y Castilla, y se despedía en el mismo tono laudatorio: muytalto, muy nobre, e muy poderoso Principe, nosso muy amado e muy preçado irmaão e amigo, Dios vos aia em Sua guarda e encommenda e acrecente vosso stado e honnra! ${ }^{81}$. En las varias cartas que dirigió a Enrique IV en el año 1405, João I utilizó de nuevo términos semejantes. Casi todas, además de registrar los vocablos "hermano" y "amigo", informaban de cómo se encontraba la familia real portuguesa; y en ellas también se pedía a Enrique IV que diese noticias de la propia:

Fazemos vos saber que, ao tempo da feitura desta nossa carta, Nos e a Reynha vossa Irmaã, minha molher, e os Iffantes vossos sobrinhos, a Deos graças somos saãos e ledos, e com plazer, as quaees novas Nos e ela e os dittos vossos sobrinhos deseiamos de vos e da Reynha vossa molher, e de todos vossos filhos ameude ouuyr.

E porem vos rogamos aficadamente que o mais ameude que o fazer poderdes vos plaza de nos certificar por vossas cartas de vossa saúde e stado e da Reynha e dos dittos vossos fllhos. E fazer-nos-edes em ello plazer grande por que he cousa com que major consolaçom e folgança avemos ${ }^{82}$.

Es obvio que por parte de la reina el interés por mantener los lazos afectivos con su hermano era aún más fuerte. En la única carta que se con-

\footnotetext{
${ }^{80}$ Ibidem, "trespuissant Prince, mon treshonuré et tresredoubté seigneur, je me recomand a vous le plus entièrement que say ou puisse, de trestout mon cuer desirante de vous et de vostre treshaute roial estat d'oier et savoir bones et gracieuses novelles, desquelx je pri a Dieu q'il me lesse toudiz avoir si bones come mon cuer desir ou come vous saveréz mesmes mielx deviser, a la tresparfaite léésce et sovereigne confort de moy".

${ }^{81}$ Hingeston 1860, [LXXI], pp.191-194.

${ }^{82}$ Hingeston 1965, [CXC], pp. 87-91.
} 
serva, firmada de su puño y letra, dirigida a Enrique IV, Felipa mantiene el tono respetuoso -Muito alto e muito poderoso príncipe ${ }^{83}$ - pero añade meu especialmente bem amado irmão; y se encomienda humildemente, de todo corazón, a su alta nobleza. Se dice ansiosa por recibir noticias sobre la salud y los logros de su hermano, y segura de que él también querrá saber que su hermana, el rey de Portugal su cuñado, y todos sus sobrinos se encuentran bien ${ }^{84}$.

Las cartas que Felipa dirigió a sus primos Thomas Arundel, arzobispo de Canterbury, y Henry, obispo de Norwich, ambas escritas en un momento particularmente difícil para su reino de origen, también muestran cuál era la noción de familia que la reina tenía, y hacia dónde entendía que debía extenderse su acción política. Datan del año 1399 y están relacionadas entre sí. Ambas hacen referencia al cambio de gobierno en Inglaterra, en el que estaban involucrados familiares muy próximos a la reina; y ésta utilizó su influencia para intentar apaciguar algunos de los conflictos que existían entre personas que le eran queridas.

Henry Despenser, obispo de Norwich, había caído en desgracia a ojos del hermano de Felipa cuando aún no era Enrique IV, pero sí duque de Lancáster y de Hereford. En una carta dirigida al arzobispo de Canterbury, Thomas Arundel, Felipa le pedía que secundase sus esfuerzos para tratar de conseguir que su hermano perdonase al obispo, pues el conflicto le preocupaba. Las diligencias de la reina llegaron a oídos del propio Henry Despenser, y éste le agradeció por carta no sólo la mediación a su favor que había llevado a cabo ante diversas instancias, y el hecho de haber intercedido con su hermano tratando de que le perdonase, sino también la misiva que le hizo llegar por medio de una de sus doncellas, transmitiéndole aliento. La caída de Ricardo II debía ser ya inminente, pues el obispo Despenser se confiesa en su carta muy débil de salud, aunque aliviado por las noticias que le habían dado sobre su regia prima.

Las expresiones de familiaridad siguen estando presentes en estas últimas cartas. Felipa llama a Thomas Arundel Reverendo pai em Deus, pero también muy querido y amado primo; además de saludarle de corazón y mos-

\footnotetext{
83 “Tres haut et três puissant prince", Entwistle, Russell 1940, p. 22.

84 "Sovereynement desirant doier et souvent savoir de Vostre estat et santié et en especial de la prosperitee de Vostre tres gentil persone si bons plesantes et joieuses novelles come vous mesme tres noble prince meulx les savez deviser ou en ascune manière souheider pur vostre sovereyn ease et confort. Et pur ce que je suy certeine que vous tres volontiers en oirez semblablement decea Vous signifie que le Roy mon Seigneur soverein tous mes enfans vos entiers nepveuz que toutdis se recomandent tres humblement a vous et moy leur miere Vostre entiere suer al feisance dycestes estioms tres tous seins et hettez de corps Regracioms nostre Createur que tousjours vous veulle mentenir en honeur et prosperitee selon Vostre desir", Entwistle, Russell 1940,p. 22.
} 
trar deseos de ser informada de cómo estaba ${ }^{85}$. Utiliza el mismo tratamiento con Henry Despenser, refiriéndose a él como muy querido y bien amado pri$m o^{86}$. Este último, sin embargo, en su carta dirigida a la reina para manifestarle su gratitud, es más respetuoso, evita aludir al parentesco existente entre ambos, y sólo en la parte final de la epístola, cuando se despide, se llama a sí mismo vosso muito humilde capelão e orador (...) e se vos praz, vosso primo se disso sou digno ${ }^{87}$.

La última de las cartas escritas por la reina al obispo de Norwich, y también la última de este conjunto, nos permite saber que el agradecido primo había enviado a Felipa, por medio de dos legados -el tesorero Thomas Payn y el heraldo Arundel-, paños de Reims y de lana, y unos pequeños bolsos, que ella apreció mucho. Deducimos de ello que la intervención de Felipa había surtido efecto; tal y como sucediera en una época anterior -en 1393-, cuando, a pedido de su prima, Ricardo II concedió el perdón a un empleado del puesto aduanero de King's Lynn acusado de matar a un banquero ${ }^{88}$.

Felipa de Lancáster tenía, por tanto, noción de que, incluso desde la distancia, podía cambiar el rumbo de algunas situaciones; y de que, dándose éstas dentro de su esfera familiar y en el ámbito de lo que conocía, esa intervención le competía. A ello debió contribuir el constante vaivén de ingleses y portugueses entre los dos reinos, que permitía a la reina mantenerse al tanto de lo que ocurría en su isla natal. De este modo debió recibir, con satisfacción, la noticia de la aceptación por parte del Parlamento de Londres de la candidatura de su hermano al trono de Inglaterra. Más tarde, siendo ya rey Enrique IV, la reina de Portugal propuso cimentar las relaciones entre las dos cortes -inglesa y portuguesa- a través de un enlace matrimonial anglo-portugués ${ }^{89}$. Acordado entre los dos hermanos ${ }^{90}$, el matrimonio uniría a Beatriz -hija natural

${ }^{85}$ Legge 1941, [287], p. 347: “nous vous saluons d'entier coer, en desiderantz toutdis d'oier et savoir continuelment bones novelles de vous et de vostre honurable estat, liquel li tout puissant toutz jours veulle meinteignere et gardere en honure et prosperité".

${ }^{86}$ Ibidem, [307], p. 372: "reverent père en Dieu, mon treschier et tresenterement bien amee cousyn, je vous salue tressovent et du cuer".

${ }^{87}$ Ibidem, [297] pp. 360-361: "tres excellente et tresredoubté, tres gracieuse et ma souveraigne dame, je me recomand a vostre tres hautisme nobleie aussi humblement et obessantement come ascun loial coer en ascun manere sciêt ou pluis puist (...). Vostre tres humble chapellain et orateur Henry Evesque de Norwicz, et si plesire vous soit, vostre cousin si j'estoy digne".

${ }^{88}$ Russell 2000, p. 580.

${ }^{89}$ Ibidem, p. 582.

${ }^{90}$ La reina Felipa reconoce en una carta que escribió a su hermano el 4 de noviembre de ese mismo año: "que vous le savez bien qu'il (le Comte d'Arundel) est ore mariee nom pas, par son proper movement, mes eins par votre comandement en partie, a l'instance de moi", Hingeston 1965, vol. CXCIII, pp. 99; Russell 2000, p. 582. 
del rey de Portugal, nacida probablemente en $1380^{91}$ - con Thomas Fitzalan, primo de los Lancáster y un gran apoyo para el nuevo rey de Inglaterra, que acababa de tomar posesión del condado de Arunde ${ }^{92}$. Las negociaciones no dejaron, con todo, de ser complejas. El enlace obligó a llevar a cabo muchas acciones diplomáticas, a que Felipa, João I y Enrique IV intercambiasen muchas misivas, y a que interviniesen otros negociadores ${ }^{93}$. Tras largos meses de conversaciones, el 26 de noviembre de 1405 , en Lambeth ${ }^{94}$, cerca de Londres, el propio Enrique IV entregó a Beatriz a su esposo ante el arzobispo de Canterbury, primado de Inglaterra, estando presentes el hermano de la novia, Alfonso, conde de Barcelos, y algunos de los principales magnates del reino ${ }^{95}$. El feliz éxito de esta iniciativa llevó a Peter Russell a extraer buenos argumentos para sustentar la tesis de que fue la personalidad de la reina la que hizo que la relación entre Portugal e Inglaterra evolucionase más allá de una formal alianza militar y comercial $l^{96}$.

\section{LA INFLUENCIA EN LA CORTE}

La reina inglesa también dejó en la corte portuguesa una marca duradera. Según los cronistas, siguió rezando las horas canónicas según la costumbre de Salisbury, hábito que transmitió a sus hijos y que hizo aprender a los clérigos de la corte ${ }^{97}$. No hay indicios de que ni este ritual ni la liturgia que le correspondía se impusiesen más allá de las capillas reales; pero los reglamentos que mandarían elaborar don Duarte y don Pedro, hijos de Felipa, estaban claramente influidos por las reglas que se aplicaban en la corte ingle$\mathrm{sa}^{98}$. Con todo, fue especialmente en la organización y administración de los bienes que sustentaban la casa de la reina en donde Felipa demostró sus dotes de reformadora.

El rey de Portugal concedió a Felipa ciertas rentas para el mantenimiento de su casa apenas contrajeron matrimonio ${ }^{99}$. Desde ese momento y hasta inicios del siglo XV el número de mujeres -en su mayoría viudas o

\footnotetext{
${ }^{91}$ Marques 1981,pp. 479-480.

${ }^{92}$ Goodman 1972, p. 204: "most of the rest of his life was passed fighting against the domestic and foreign enemies of the house of Lancaster", Mc Farlane 1972, p. 65.

${ }^{93}$ Silva 2007.

${ }^{94}$ Walsingham, 1874, vol. II, p. 272; Sousa 1947, vol. I, p. 391.

${ }^{95}$ Sousa 1947, vol. I, p. 391.

${ }^{96}$ Russell 2000, p. 583.

${ }^{97}$ Lopes 1983, vol. II, pp. 225-226; Zurara 1985, p. 100; Álvares 1960, p. 8.

${ }^{98}$ Gomes 1995, p. III.

${ }^{99}$ Lopes 1983, vol. II, pp. 24-25.
} 
solteras- que rodeaban a la reina, así como el de servidores de su casa, no cesaron de $\operatorname{crecer}^{100}$. En los listados de los moradores de su casa, aparecen algunos nombres de ingleses ocupando ofícios cercanos a la reina sobre todo, pero curiosamente, ninguna mujer ${ }^{101}$. Felipa poseía su propia cancillería, tenía su propio escribano de la poridad, también un tesorero - para cuyos cargos escogía normalmente ingleses-, un oidor para regir conjuntamente sus tierras, y bajo su mando a muchos funcionarios encargados de administrar su casa, y las villas cuya jurisdicción y derechos reales le pertenecían.

Conocemos hoy relativamente bien el modo en que la reina administraba su señorío porque, en las villas que pertenecían a su jurisdicción, Felipa de Lancáster -y después sus sucesoras-instituyó la exigencia a los concejos de que registrasen en un libro todos los documentos que les eran enviados por ellas o por los reyes, así como cualquier otra carta de interés municipal. El 5 de abril de 1410, por ejemplo, la reina explicaba, en un documento enviado a todas sus tierras, que debían copiar esa carta en pública forma y registrarla nos livros desses concelhos -en los libros de esos concejos-, divulgando después su contenido a través de uno de los porteros, que debía ser enviado a todos los puntos del término, em tal guissa que todos ajam notiçia dela -de tal modo que todos tengan noticia de ella ${ }^{102}$.

Felipa también se preocupó por clarificar cuáles eran los límites entre su jurisdicción y la de su esposo el rey en las tierras que le fueron concedidas en arras cuando ambos contrajeron matrimonio. La reina tenía en cada una de las villas de su señorío un escribano y algunos funcionarios encargados de recaudar las rentas y derechos que le pertenecían. El monarca, sin embargo, seguía teniendo alguna autoridad sobre estos lugares, especialmente en asuntos de naturaleza militar, y también en algunos de tipo judicial. Pese a ello, Felipa alegaba que le pertenecía toda la jurisdicción -alta y baja, mero y mixto imperio- en sus tierras; y entendía que competía a ella, a través de sus oficiales, la vigilancia de las actividades de los magistrados locales y señoriales. Igualmente, creía que todas las apelaciones judiciales debían llegar a ella, para se acabar toda jurdiçom em sua pesoa -de tal modo que toda jurisdicción acabase en su persona-. João I acabó prohibiendo a sus oficiales que diesen cartas, mandatos y albaranes, y limitando el ejercicio de su autoridad sobre los moradores de las tierras de la reina apenas a materias de índole militar o de naturaleza específicamente fiscal -como el cobro de las

${ }^{100}$ Silva 2010,pp. 207-227.

${ }^{101}$ Monumenta Henricina 1960, vol. I, pp. 289-293. Felipa acogía además en la corte a visitas femeninas de Inglaterra que le servían de intermediarias con los familiares distantes, Legge 1941, [297] pp. 360-361.

${ }^{102}$ AHCMO, Tombo do Concelho de Óbidos, f. 6v. 
sisas- o extraordinaria, pues aceptaba que ello casaba con la tradición de las tierras de las reinas ${ }^{103}$.

El patrimonio que sustentaba la casa de la reina se convirtió en fijo tras la muerte de Felipa, y a cada donataria posterior se le recordó que poseía las tierras assy e tam compridamente como todo esto ouиe a rrainha dona philippa -así y tan cumplidamente como esto tuvo la reina doña Felipa ${ }^{104}-$. De este modo, puede decirse que el periodo en el que Felipa de Lancáster estuvo al frente de la casa de la reina fue esencial para la estructuración de esta institución como organismo autónomo dentro de la corte regia. El legado de Felipa se revela, así, más importante de lo que en el pasado se pensó; y su figura mucho mayor que la de buena esposa y madre ejemplar con la que normalmente se la identifica.

\section{BIBLIOGRAFÍA CITADA}

Álvares, Frei João (1960), Trautado da vida e feitos do muito virtuoso Senhor Ifante D. Fernando, Obras, ed. Adelino de Almeida Calado, Coimbra, Atlantida.

Amaral, Luís Carlos; Barroca, Mário Jorge (2012), A Condessa-Rainha. Tere$s a$, Rio de Mouro, Círculo de Leitores.

Baleiras S. Campos, Isabel Maria Garcia de Pina N. (2008), Leonor Teles, uma mulher de poder?, Lisboa, Faculdade de Letras da Universidade de Lisboa (tesis de máster en Historia medieval de Portugal, inédita).

Baleiras, Isabel de Pina (2012), Uma rainha inesperada. Leonor Teles, Rio de Mouro, Círculo de Leitores.

Benevides, Francisco da Fonseca (2007), Rainhas de Portugal. Estudo Histórico, edición facsímil de la obra original de 1878, Lisboa, Typographia Castro Irmão - Livros Horizonte.

Chancelarias Portuguesas: D. Duarte (1998), vol. III, Lisboa, Centro de Estudos Históricos, Universidade Nova de Lisboa.

Chancelarias Portuguesas: D. João I (2004), vol. IV, Lisboa, Centro de Estudos Históricos, Universidade Nova de Lisboa.

Coelho, Maria Helena da Cruz (2005), D. João I. O que re-colheu Boa Memória, Lisboa, Círculo de Leitores.

Duggan, Anne (ed.) (1997), Queens and Queenship in Medieval Europe, Woodbridge, The Boydell Press.

${ }^{103}$ AHCMO, Tombo do Concelho, f. 11-12.

${ }^{104}$ AN-TT, Chancelaria de D. Afonso V, L ${ }^{\circ} 25$, f. $51 \mathrm{v}$. 
Earenfight, Theresa (ed.) (2005), Queenship and Political Power in Medieval and Early Modern Spain, Aldershot - Burlington, Ashgate.

Earenfight, Theresa (2013), Queenship and Power. Queenship in Medieval Europe, Nueva York, Palgrave MacMillan.

Echevarría, Ana (2002), Catalina de Lancaster. Reina Regente de Castilla (1372-1418), Fuenterrabía, Nerea.

Entwistle, William James; Fuenterrabía, Peter E. (1940), A Rainha D. Filipa e a sua Côrte, en A Rainha D. Filipa e a sua corte, Lisboa, Comissão Executiva dos Centenários, pp. 319-346 (Congresso do Mundo Português, Publicações; 2).

Figanière, Frederico Francisco de la (1859), Memórias das Rainhas de Portugal (D. Theresa - Santa Isabel), Lisboa, Typographia Universal.

Gomes, Rita Costa (1995), A corte dos Reis de Portugal no Final da Idade Média, Linda-a-Velha, DIFEL.

Goodman, Anthony (1972), A History of England from Edward II to James I, Longman Group Limited.

Hingeston, Rev. Francis Charles (ed.) (1860), Royal and Historical Letters during the reign of Henry the Fourth King of England and France and Lord of Ireland, A.D. 1399-1404, vol. I, Londres, Longman, Green, Longman, and Roberts.

Hingeston, Rev. Francis Charles (ed.) (1965), Royal and Historical Letters during the reign of Henry the Fourth King of England and France and Lord of Ireland, A.D. 1405-1413, vol. II, Londres, Public Record Office.

Legge, M. Dominica Legge (ed.) (1941), Anglo-Norman Letters and Petitions from All Souls Ms.182, Oxford, Blackwell.

Lopes, Fernão (1983), Crónica de D. João I, 2 vols., Lisboa, Livraria Sá da Costa.

Lourenço, Maria Paula Marçal (1995), A Casa do Infantado (1654-1706), Lisboa, Junta Nacional de Investigação Científica, Centro de História da Universidade de Lisboa.

Lourenço, Maria Paula Marçal (1999), Casa, Corte e Património das Rainhas de Portugal (1640-1754), 4 vols., Lisboa, Faculdade de Letras da Universidade de Lisboa (tesis de doctorado en Historia).

Marques, A. H. de Oliveira (1981), Lencastre, D. Filipa de (1360-1415), en Serrão, Joel (coord.), Dicionário de História de Portugal, Porto, Livraria Figueirinhas, vol. III, pp. 479-480.

McFarlane, K. B. (1972), Lancastrian Kings and Lollard Knights, Oxford, Clarendon Press. 
Merêa, Paulo (1937), Um problema filológico-cirúrgico: a palavra "arras”, "Novos Estudos de História do Direito" 1, pp. 139-149.

Merêa, Paulo (1952), O dote nos documentos dos séculos IX-XII (Astúrias, Leão, Galiza e Portugal), en Merêa, Paulo (ed.), Estudos de Direito Hispânico Medieval, Coimbra, Universidade, vol. I, pp. 59-77.

Monumenta Henricina (1960), Portugal, Coimbra, Comissão Executiva das Comemorações do Quinto Centenário da Morte do Infante D. Henrique, vols. I-II.

Monteiro, J. P. Franco (1893), As Donatarias de Alenquer. História das rainhas de Portugal e da sua casa e estado, Lisboa, M. Gomes Editor.

Olivera Serrano, César (2005), Beatriz de Portugal. La Pugna Dinástica AvísTratámara, Santiago de Compostela, La Coruña, CSIC (Cuadernos de Estúdios Gallegos; Anexo 35).

Parsons, John Carmi (ed.) (1998), Medieval Queenship, Stroud, Sutton Publishing.

Perroy, Edouard (ed.) (1933), The Diplomatic Correspondence of Richard II, Royal Historial Society, Londres, Offices of the Society (Camden Third Series; 48).

Rodrigues, Ana Maria S. A. (1995), Poderes Concorrentes e seus Agentes na Torres Vedras Quatrocentista, en Amar, Sentir e Viver a História. Estudos de Homenagem a Joaquim Veríssimo Serrão, Lisboa, Colibri, pp. 49-72.

Rodrigues, Ana Maria S. A.; Silva, Manuela Santos (2010), Private Properties, Seigniorial Tributes and Jurisdictional Rents: the Income of the Queens of Portugal in the Middle Ages, en Earenfight, Theresa (ed.), Women and Money in Medieval Europe, [S.1.], Palgrave Macmillan, pp. 209-228.

Rodrigues, Maria Teresa Campos (1981), Coimbra, cortes de (1387), en Serrão, Joel (dir.), Dicionário de História de Portugal, Porto, Livraria Figueirinhas, vol. VI, p. 400.

Russell, Peter E. (1955), The English Intervention in Spain and Portugal in the Time of Edward III \& Richard II, Oxford, Clarendon Press.

Russell, Peter E. (2000), A Intervenção Inglesa na Península Ibérica durante a Guerra dos Cem Anos, Lisboa, Imprensa Nacional-Casa da Moeda.

Silleras Fernández, Núria (2003), Queenship en la Corona de Aragón en la Baja Edad Media: estudio y propuesta terminológica, "La Corónica. A Journal of Medieval Spanish Language and Literature" 32/1, pp. 119-133.

Silva, Manuela Santos (1994), Óbidos Terra que foi da Rainha D. Filipa (O Senhorio de Óbidos de 1415 a 1428), en A região de Óbidos na Épo- 
ca Medieval.Estudos, Caldas da Rainha, Património Histórico - Grupo de Estudos, pp. 85-109.

Silva, Manuela Santos (2007), O casamento de D. Beatriz (filha natural de D. João I) com Thomas Fitzalan (Conde de Arundel) paradigma documental da negociação de uma aliança, en Problematizar a História, Estudos de História Moderna em Homenagem a Maria do Rosário Themudo Barata, Lisboa, Caleidoscópio - Centro de História da Universidade de Lisboa, pp. 77-91.

Silva, Manuela Santos (2010), A Casa e o Património da Rainha de Portugal D. Filipa de Lencastre: um ponto de partida para o conhecimento da Casa das Rainhas na Idade Média, "Revista Signum" 11/2, pp. 207-227.

Silva, Manuela Santos (2013), El señorío urbano de las reinas-consortes de Portugal (siglos XII-XV), en Solorzano Teléchea, Jesús Ángel; Arízaga Bolumburu, Beatriz; Andrade, Amélia Aguiar (eds.), Ser Mujer en la Ciudad Medieval Europea, Logroño, Instituto de Estudios Riojanos, pp. 271-288.

Silva, Manuela Santos (2014), Filipa de Lencastre. A Rainha Inglesa de Portugal, Lisboa, Temas \& Debates.

Sousa, D. António Caetano de (1946), História Genealógica da Casa Real Portuguesa, Nova Edição Revista, vol. II, Coimbra, Atlântida.

Sousa, D. António Caetano de (1947), Provas da História Genealógica da Casa real Portuguesa, vol. I, Coimbra, Atlântida (2. ${ }^{\mathrm{a}}$ ed.).

Sousa, Armindo de (1990), As Cortes Medievais Portuguesas (1385-1490), vol. I, Porto, Instituto Nacional de Investigação Científica, Centro de História da Universidade do Porto.

Stafford, Pauline (1983), Queens, Concubines and Dowagers. The king's wife in the Early Middle Ages, Athens, GA, Universidad de Georgia Press.

Stafford, Pauline (1998), Queens, Concubines and Dowagers. The king's wife in the Early Middle Ages, Londres - Washington, Leicester University Press.

Valdeón Baruque, Julio (2001), Los Trastámaras. El Triunfo de una Dinastía Bastarda, Madrid, Ediciones Temas de Hoy.

Vann, Theresa M. (ed.) (1993) Queens, Regents, and Potentates, Cambridge, Academia Press.

Walsingham, Thomas (1874), Chronicon Angliae, ab Anno Domini 1328 usque ad annum 1388, ed. Edward Maunde Thomson, II vols., Londres, - Oxford - Cambridge - Edimburgo - Dublin, Longman \& Co. - Trubner \& Co. - Parker \& Co. - Macmillan \& Co. - A \& C. Black - A. Thom. 
Woodacre, Elena (ed.) (2013), Queenship in the Mediterranean. Negotiating the Role of the Queens in the Medieval and Early Modern Eras, Nueva York, Palgrave MacMillan.

Zurara, Gomes Eanes de (1985), Crónica da Tomada de Ceuta, prefácio e actualização de textos de Carlos Miranda, Lisboa, Editorial Escol.

Fecha de recepción del artículo: mayo 2015

Fecha de aceptación y versión final: febrero 2016 